\title{
Observed transport estimates between the North Atlantic and the Arctic Mediterranean in the Iceland-Scotland region
}

\author{
Svein Østerhus, William R. Turrell, Bogi Hansen, \\ Peter Lundberg \& Erik Buch
}

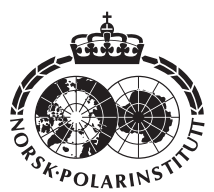

\begin{abstract}
The Arctic Mediterranean is the ocean area north of the Greenland-Scotland Ridge. Exchanges between this region and the North Atlantic both provide the main source for production of North Atlantic Deep Water and supply heat and salt to the northern oceans. The exchange occurs through several gaps in the ridge; in terms of volume flux the Iceland-Scotland Gap is the most important one as it carries more than half the total, with approximately three quarters of the total inflow and one third of the total outflow. The Nordic WOCE observational system was initiated to monitor the exchanges through this gap and it has provided data that allow estimates of typical fluxes and their seasonal variation. The flux measurements show that most of the Atlantic inflow to the Arctic Mediterranean returns as overflow and hence the processes forming intermediate and deep waters in the Arctic Mediterranean are the main forcing mechanism for the Atlantic inflow. The inflow between Iceland and Scotland seems to be a maximum in late winter while the Faroe Bank Channel overflow is strongest in late summer. Using the results from the Nordic WOCE system it has been possible to interpret historical observations from Ocean Weather Ship Station M and conclude that the flux of the Faroe Bank Channel overflow decreased in magnitude from 1950 to 2000.
\end{abstract}

S. Østerhus, Bjerknes Centre for Climate Research and Geophysical Institute, University of Bergen, Allégaten 70, N-5007, Bergen, Norway; W. R. Turrell, Marine Laboratory, Victoria Road 90, Aberdeen AB11 9DB, UK; B. Hansen, Faroese Fisheries Laboratory, Box 3051, FO-110 Torshavn, Faroe Islands; P. Lundberg, Meteorological Institute, University of Stockholm, Sweden; E. Buch, Danish Meteorological Institute, Lyngbyvej 100, DK-2100 Copenhagen, Denmark.

The Arctic Mediterranean consists of the Arctic Ocean and the Nordic seas (the Norwegian Sea, the Iceland Sea and the Greenland Sea). In this region, cooling and brine rejection increase the density of upper layer waters sufficiently so that they may descend to intermediate $(500-1000 \mathrm{~m})$ or deep levels. These "ventilated" waters leave the Arctic Mediterranean as deep "overflow" across the Greenland-Scotland Ridge into the North Atlantic (Fig. 1), and together with ambient water entrained en-route, they become the main source of North Atlantic Deep Water, NADW (Dickson \& Brown 1994). To balance the overflow and the surface outflows through the Denmark Strait and through the Canadian Archipelago, a large inflow is needed and most of it derives from the North Atlantic. This inflow of warm, saline Atlantic Water is generally considered to be the main reason for the relatively mild climate of large parts of the Arctic Mediterranean as well 


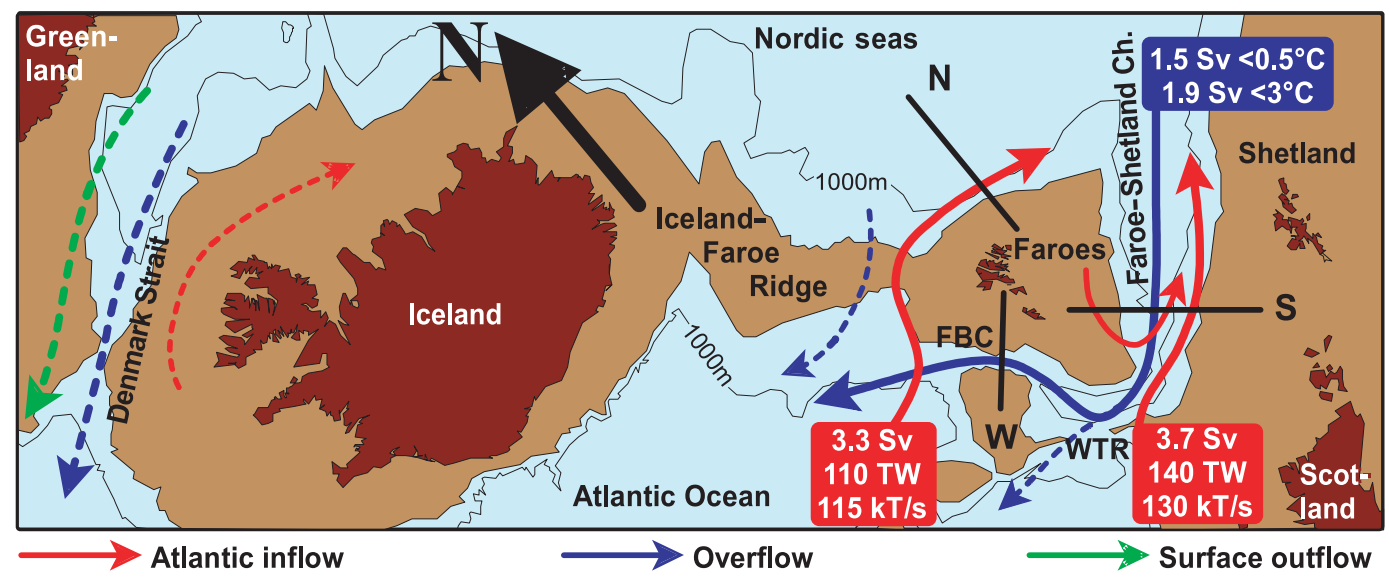

Fig. 1. The Greenland-Scotland Ridge (light brown areas are shallower than $500 \mathrm{~m}$ ) separates the Nordic seas from the Atlantic. Continuous arrows indicate exchanges monitored by the Nordic WOCE system. Broken arrows indicate other exchanges. Numbers indicate typical fluxes of water in $\mathrm{Sv}\left(1 \mathrm{~Sv}=10^{6} \mathrm{~m}^{3} \cdot \mathrm{s}^{-1}\right)$, heat in TW $\left(1 \mathrm{TW}=10^{12} \mathrm{~W}\right)$, and salt in kilotonnes per second. Thick black lines indicate sections monitored by the observational system. FBC denotes the Faroe Bank Channel, and WTR the Wyville-Thomson Ridge.

as much of northern Europe (Rahmstorf \& Ganopolski 1999). It is also a mechanism for transporting salt, and hence density, to the ventilation areas.

The exchanges of water, heat and salt between the North Atlantic and the Arctic Mediterranean are therefore critical for maintaining the presentday global thermohaline circulation as well as the climatic conditions in the region. This has been the motivation for establishing the observational system discussed in this paper. It was initiated as part of the Nordic World Ocean Circulation Experiment (WOCE) project, which also included observations in the Denmark Strait; here we discuss only the observations in the Iceland-Scotland region. Monitoring the fluxes of Atlantic Water entering the Arctic Mediterranean between Iceland and Scotland and of the overflow through the Faroe Bank Channel, the system has been in operation from 1994 up to the present, with funding from various sources. In this overview paper, we describe the Nordic WOCE system, list the main data sets acquired, and review some of the main results.

\section{The observational system}

The Nordic WOCE system is based on a combination of regular CTD standard sections and quasi- permanent ADCP moorings along or close to the section lines (Fig. 2). These sections cross the two main inflow branches as well as the overflow through the Faroe Bank Channel (Fig. 1). The CTD observations on the standard section in the Faroe-Shetland Channel (section S on Fig. 2) are the continuation of a long-term series of regular classical hydrographic observations that started in the beginning of the 20th century. This section is now occupied four to seven times a year with Scottish and Faroese research vessels. The other two sections (W and $\mathrm{N}$ on Fig. 2) were initiated in the late 1980s and are occupied four times a year by a Faroese research vessel.

The ADCP moorings started operation in 1994 and are now continuous except for about three weeks of servicing once a year. Each mooring has one upward-looking ADCP (Acoustic Doppler Current Profiler) which every 20 minutes measures a velocity profile in 20 - 25 separate layers that cover most of the water column above the instrument. Most of the ADCPs are $75 \mathrm{kHz}$ instruments, manufactured by RDI, mounted at the top of single point moorings with the ADCP at $600-840 \mathrm{~m}$ depth. Three of the standard sites are sufficiently shallow, however, that $150 \mathrm{kHz}$ instruments could be used, but they require special protection from fisheries. At site SE (Fig. 2) the mooring has been located in protected areas associated with offshore oil exploration, but at 


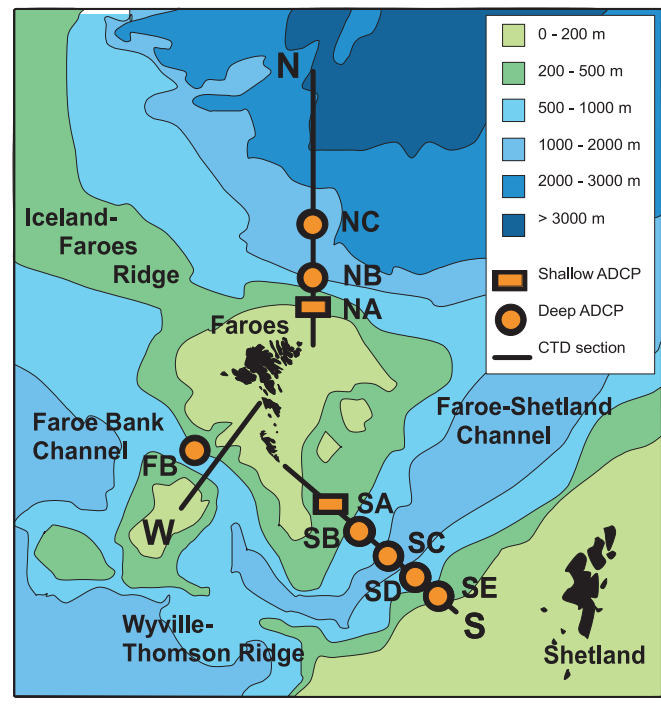

Fig. 2. The observational system covers the two main Atlantic inflow branches and the Faroe Bank Channel overflow with CTD sections (black lines) and ADCP moorings (orange circles and rectangles), identified by two-letter labels. In addition to the standard mooring sites shown, there have been a few short-term deployments at other sites.

sites NA and SA, special trawl-protecting frames had to be developed.

\section{Data sets}

The hydrographic data set includes observations of temperature and salinity from more than 150 cruises at section S (Fig. 2) dating back to 1903, and more than 50 cruises at sections $\mathrm{N}$, and $\mathrm{W}$ dating back to 1988 . At section $\mathrm{S}$, the data were acquired by Nansen bottle casts at standard depths until 1994, after which time CTDs have been used. At the other two sections, CTDs have been used throughout the period. Various instruments and acquisition and calibration procedures have been in use and the data quality is variable. For flux calculations of the various water masses, we have used only the modern data where the quality is well beyond the requirements.

At the beginning of the observational period, instrumental problems with the ADCPs reduced data coverage considerably. After these were resolved there have also been occasional instrument failures in addition to problems arising from fisheries or mooring equipment. The data cov-

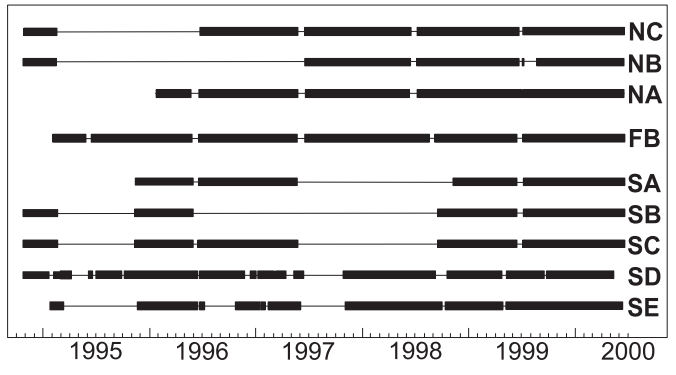

Fig. 3. Periods with good ADCP data until mid-summer 2000 at each of the standard mooring sites (Fig. 2). At sites SD, and $\mathrm{SE}$, measurements made available by the offshore industry are included.

erage (Fig. 3) is therefore not continuous; but exchange of data with the offshore industry has enhanced the coverage over the Scottish slope considerably.

\section{Flux estimates}

The gaps in data coverage complicate the simultaneous evaluation of fluxes of various branches. We therefore expect estimates to be refined as the measurements continue. Nevertheless, it appears that the data already acquired allow consistent flux values to be evaluated for the Iceland-Scotland inflow of Atlantic Water and for the Faroe Bank Channel overflow.

The inflow of Atlantic Water to the Arctic Mediterranean is carried by three separate branches and the Nordic WOCE system monitors the two dominant ones. A section crossing both of these flows (sections $\mathrm{N}$ and $\mathrm{S}$ on Fig. 2 combined) shows the Atlantic Water, characterized by high salinities, focused over the two slope regions north of the Faroes and west of Shetland, respectively, while there is a weaker return flow on the Faroese side of the Faroe-Shetland Channel (Fig. 4). From the measurements, we have estimated the average flux of Atlantic Water to be $3.3 \mathrm{~Sv}\left(10^{6}\right.$ $\mathrm{m}^{3} \cdot \mathrm{s}^{-1}$ ) between Iceland and the Faroes (Hansen et al. 1999) and $3.7 \mathrm{~Sv}$ between the Faroes and Shetland (Turrell et al. 1999). The heat and salt fluxes of these two branches have also been estimated (Fig. 1).

The Faroe Bank Channel is the deepest passage across the Greenland-Scotland Ridge and is the main outlet for the coldest deep water produced in the Arctic Mediterranean. The deepest 

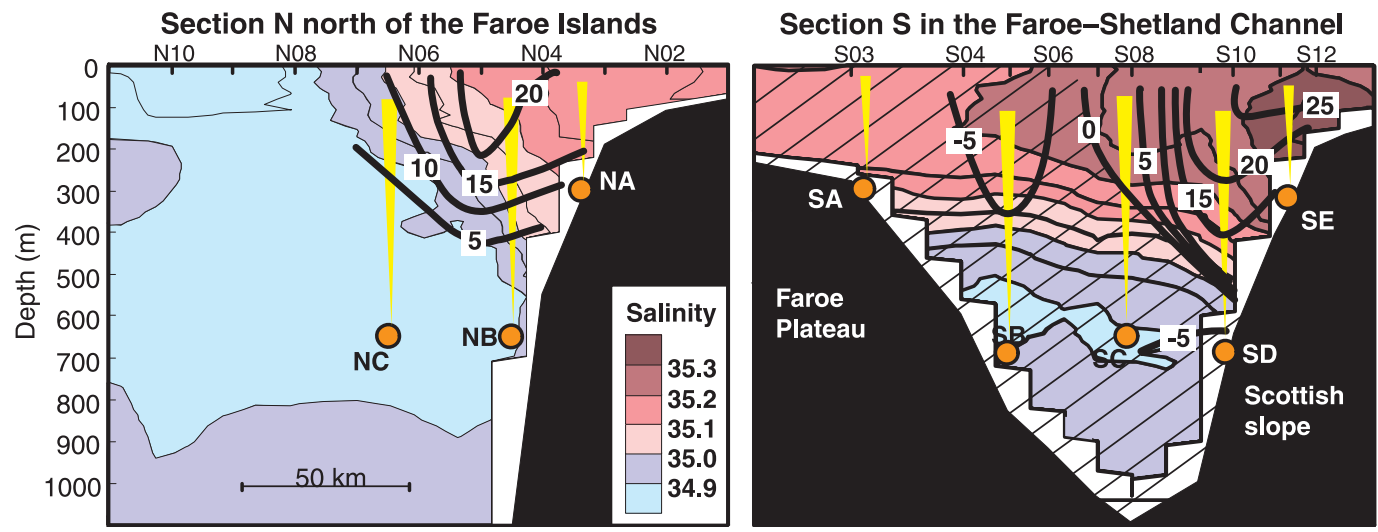

Fig. 4. Average salinity (colour) on sections N and S (Fig. 2) and average velocity perpendicular to the sections shown by isolines with velocity in $\mathrm{cm} \cdot \mathrm{s}^{-1}$ (positive towards the east and north-east, respectively). Hatched area indicates flow towards the Atlantic. Standard mooring sites with ADCPs indicated by orange circles with soundbeams illustrated as yellow cones. Labels above the sections indicate every second standard station.

parts of the channel are constantly filled with cold overflow water which flows into the Atlantic with average velocities exceeding $1 \mathrm{~m} \cdot \mathrm{s}^{-1}$ in the core (Fig. 5). The $3{ }^{\circ} \mathrm{C}$ isotherm is often defined as the upper boundary of Iceland-Scotland Overflow Water (ISOW) but this definition includes some entrained Atlantic Water. Water colder than $+0.5{ }^{\circ} \mathrm{C}$ is a purer form of ventilated water (Hansen \& Østerhus 2000), consisting of Norwegian Sea Deep Water (NSDW; $<-0.5^{\circ} \mathrm{C}$ ) and Norwegian Sea Arctic Intermediate Water (NSAIW; $-0.5^{\circ} \mathrm{C}$ to $\left.+0.5^{\circ} \mathrm{C}\right)$. The ADCP moored at the sill of the channel (site FB in Fig. 2) has measured almost continuously since November 1995 (until June 2001, so far). Combining these measurements with the results from a 70 day experiment with three moored ADCPs (Fig. 5), the flux of water colder than $+0.5^{\circ} \mathrm{C}$ (NSDW + NSAIW) was estimated to be $1.5 \mathrm{~Sv}\left(10^{6} \mathrm{~m}^{3} \cdot \mathrm{s}^{-1}\right)$ and that of ISOW as $1.9 \mathrm{~Sv}$ (Østerhus et al. 1999).

Combining the flux estimates of Atlantic inflow and Faroe Bank Channel overflow from the Nordic WOCE system with estimates made by others in other areas, a consistent water balance for the Arctic Mediterranean may be established (Fig. 6). In addition to the two Atlantic inflow branches monitored by the Nordic WOCE system, there is also a branch west of Iceland which transports about $1 \mathrm{~Sv}$ of Atlantic Water (Kristmannsson 1998). Adding $1 \mathrm{~Sv}$ of inflow through the Bering Strait (Roach et al. 1995), the total inflow to the Arctic Mediterranean is about $9 \mathrm{~Sv}$, which has to be balanced by a similar flux out into the Atlantic. The overflows carry most of this outflow. Adding the Faroe Bank Channel ISOW flux to estimates for the overflow across the IcelandFaroe Ridge (1.1 Sv; Hermann 1967) and across the Wyville-Thomson Ridge (0.1 Sv; Ellett 1998), gives a total Iceland-Scotland overflow of about $3 \mathrm{~Sv}$, which is similar to the $3 \mathrm{~Sv}$ generally quoted for the Denmark Strait overflow (Dickson \& Brown 1994). Subtracting the total overflow from the total inflow leaves a flux of about $3 \mathrm{~Sv}$ for the outflows in the upper layers through the Canadian Archipelago and through the Denmark Strait, carried by the East Greenland Current.

The relatively low salinity Bering Strait inflow probably contributes little to the overflow, so Fig. 6 therefore implies that about three quarters of the Atlantic inflow is converted to overflow. Future refinements will no doubt modify these numbers, but fairly drastic modifications are needed to change the basic conclusion that most of the Atlantic inflow returns as overflow. This again has implications for the forcing mechanisms of the exchanges. The thermohaline ventilation that converts Atlantic Water to intermediate and deep overflow waters is the process that maintains the overflow into the Atlantic, and the removal of water by the overflow will tend to lower the sea level in the Arctic Mediterranean. The resulting sea level gradient across the ridge creates a barotropic pressure gradient that forces a compensating inflow in the surface layers. Thus, a thermohaline ventilation that induces a certain overflow flux will also induce a compensating 
Atlantic inflow of the same magnitude. This is not the only forcing mechanism operating. Estuarine forcing and forcing by wind stress are other alternatives and they may be the dominant exchange forcings for parts of the Arctic Mediterranean. However, for the Arctic Mediterranean as a whole, Fig. 6 indicates that thermohaline ventilation is the main forcing mechanism.

\section{Seasonal flux variations}

With the available data set it is possible to estimate the seasonal variation with a certain confidence. For the current flowing north of the Faroes, a clear seasonal cycle is evident for the total volume flux (Hansen et al. 2000) with maximum flux around March. Much of this water does, however, derive from the East Icelandic Current and other areas in the Arctic Mediterranean. When we consider only the part deriving from the Atlantic, the seasonal variation of the Iceland-Faroe inflow is much less pronounced and its amplitude does not seem to exceed $1 \mathrm{~Sv}$ (Hansen et al. 2000).

In the Faroe-Shetland Channel, the data coverage has not been as complete. Nevertheless, a fairly consistent picture emerges, with little or no seasonal variation of the net inflow through this channel. Our observations certainly indicate seasonal variations in the fluxes over the Scottish (south-eastern) side of the channel, as others have seen (Gould et al. 1985), but these variations seem to be compensated by similar variations in the outflow over the Faroese (north-western) side (Hansen et al. 2000). This seems to leave the Iceland-Scotland inflow of Atlantic Water with a seasonal amplitude of perhaps $1 \mathrm{~Sv}$ in magnitude

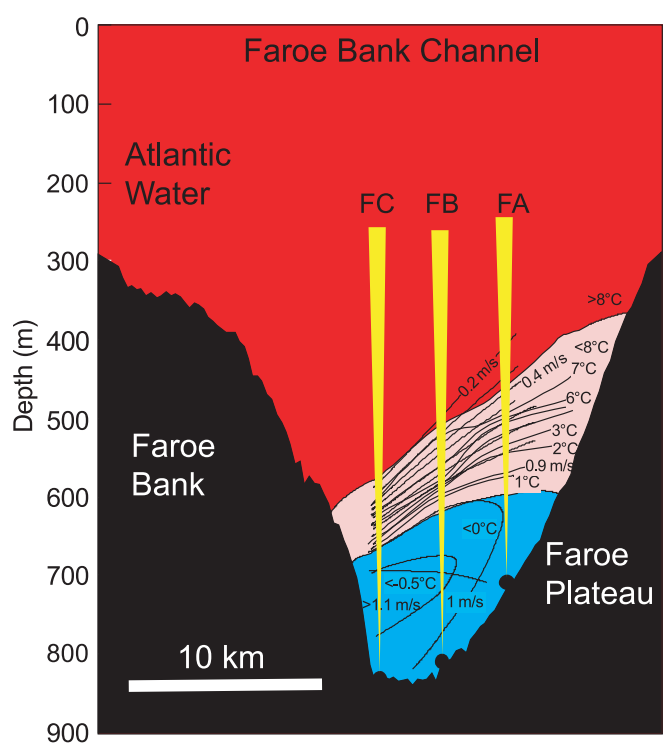

Fig. 5. A section across the Faroe Bank Channel with temperature distribution on a typical day (colour) and vectorially averaged along-channel velocity (black lines) based on 70 days of observation with three moored ADCPs (shown).

and maximum in late winter. The Atlantic inflow branch, west of Iceland, has a seasonal amplitude of similar magnitude, but out of phase, and the conclusion is that the total Atlantic inflow to the Arctic Mediterranean does not have a seasonal amplitude exceeding $15 \%$ of the mean flow (Hansen et al. 2000).

In the Faroe Bank Channel, the ADCP measurements show large fluctuations on time scales of days and weeks; when the full data set is con-

Fig. 6. A water balance for the Arctic Mediterranean.

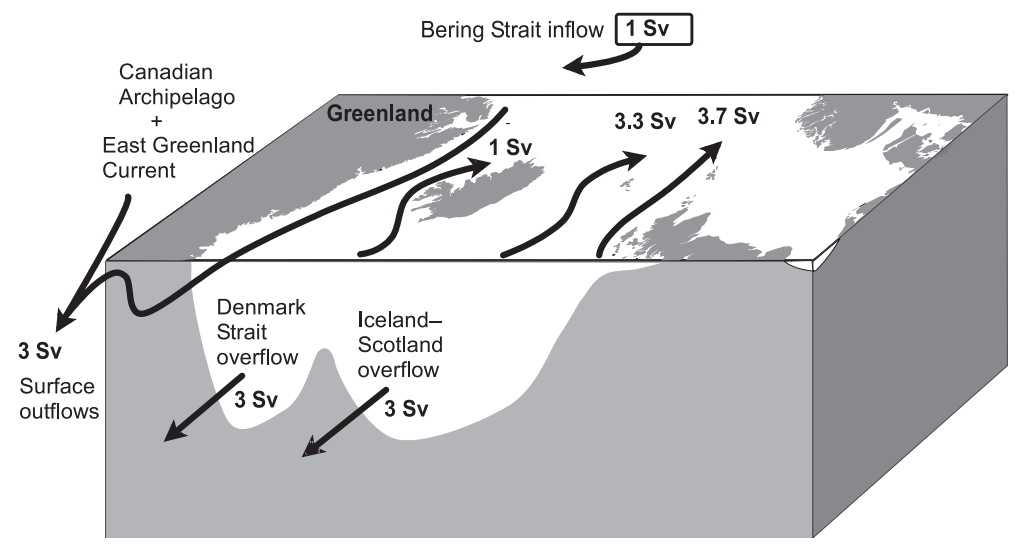




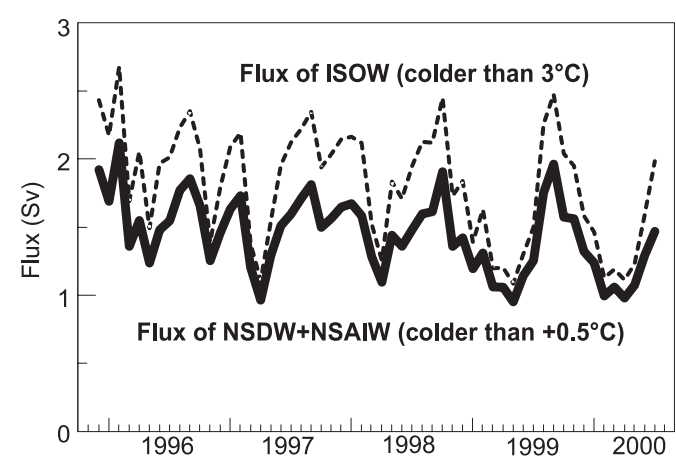

Fig. 7. Monthly averaged flux of ISOW water (dashed curve) and of NSDW+NSAIW (solid curve) overflow through the Faroe Bank Channel.

sidered, a fairly consistent seasonal cycle emerges (Fig. 7) with maximum overflow flux in August. The overflow is generated by the thermohaline ventilation processes and they are, no doubt, most intense in winter. The long delay implies propagation speeds from the formation regions to the Faroe Bank Channel on the order of centimetres per second. The amplitudes of seasonal variation in Fig. 7 are about $10-20 \%$ of the mean flow. We have no information on seasonal variation of the other two overflow paths in the Iceland-Scotland Region, but Jónsson (1999) found little seasonality in the Denmark Strait overflow

Both the total Atlantic inflow to and the total overflow from the Arctic Mediterranean, therefore, seem to have only small seasonal variations in flux relative to their magnitudes. Since they dominate the inflow and outflow, respectively, this correspondence is necessary for consistency. As noted already by Worthington (1970), there must be a fairly tight balance between total inflow and total outflow. An imbalance of $1 \mathrm{~Sv}$ would in the course of a month lead to sea level changes of about $20 \mathrm{~cm}$ averaged over the whole of the Arctic Mediterranean.

\section{Long-term flux variations}

The measurements of overflow through the Faroe Bank Channel (Fig. 7) have a downward trend that might indicate a decreasing flux, but the period of observation is still too short to conclude anything on long-term flux changes for this flow or for the Atlantic inflow based on the measurements alone. From the outset there has been the hope, however, that the detailed measurements carried out with the Nordic WOCE system could enable us to formulate and calibrate models that use historic hydrographic and/or remote sensing data sets so that long-term changes could be investigated.

This hope seems to have been fulfilled at least for the Faroe Bank Channel overflow. The driving force for this overflow is the horizontal pressure gradient along the channel axis, which is created by the ventilation processes. The top of the cold overflow water, defined by the $+0.5^{\circ} \mathrm{C}$ isotherm, follows closely the $\sigma_{t}=28.0$ isopycnal. In the Atlantic, just off the exit of the channel, this isopycnal is below the sill level of the Faroe Bank Channel, which is at about $840 \mathrm{~m}$ depth. Upstream, in the Norwegian Sea, it is found much higher in the water column, but measurements at Ocean Weather Ship Station M (OWS-M) document that this isopycnal deepened by about 50 $\mathrm{m}$ from 1950 to 2000 . The total overflow flux defined as water colder then $3{ }^{\circ} \mathrm{C}$ has densities ranging down to $\sigma_{\mathrm{t}}=27.8$, and this isopycnal has also deepened at OWS-M at similar rates since 1950. Comparing these observations to the observations in the Faroe Bank Channel, it has been proposed that this implies a weakening of the Faroe Bank Channel overflow during the latter half of the 20th century (Hansen et al. 2001). If not compensated by increases in other outflows, this implies a reduced Atlantic inflow.

\section{Outlook}

Much effort was originally put into making the Nordic WOCE observational system reliable and protected against fisheries. This has paid off in reduced equipment losses. As long as this situation continues and the necessary funding is available for consumables and instrument maintenance, the system can be expected to deliver ever more complete data sets that will allow ever more precise estimates of the typical fluxes as well as their seasonal variations. As the observational period is extended, the possibility of directly observing long-term changes will also increase.

It must be noted, however, that the observational system does not have a complete coverage, even when we restrict the discussion to the Iceland-Scotland region. In this region, the Atlantic inflow is well covered, but the overflow is only 
partly so since there is no monitoring of the overflows over the Iceland-Faroe Ridge and the Wyville-Thomson Ridge. The combined fluxes of these two overflows contribute about $20 \%$ of the total overflow based on the available (but not very complete) evidence (Hansen \& Østerhus 2000). In contrast to the Faroe Bank Channel, these two ridges are fairly shallow, but wide, and the depth of the overflow water north-east of the ridges is close to sill-level for each of them. These ridges can therefore be expected to act like "safety valves" that switch between very large and very small overflow fluxes depending on the interface depth, and they would be an important component in a complete monitoring system.

Acknowledgements.-The Nordic WOCE project was funded from the Nordic Environmental Research Programme for 1993-97 and by Nordic research councils. Continued support of the observational system has been provided from the European Community through the VEINS project (MAST IV) and the MAIA project (Framework V).

\section{References}

Dickson, R. R. \& Brown, J. 1994: The production of North Atlantic Deep Water-sources, rates, and pathways. J. Geophys. Res. 99(C6), 12,319-12,341.

Ellett, D. J. 1998: Norwegian Sea Deep Water overflow across the Wyville-Thomson Ridge during 1987-88. ICES Coop. Re, Rep. 225, 195-205.

Gould, W. J., Loynes, J. \& Backhaus, J. 1985: Seasonality in slope current transports N.W. of Shetland. ICES CM
1985/C:7. Copenhagen: International Council for the Exploration of the Sea.

Hansen, B., Jónsson, S. S., Turrell, W. R. \& Østerhus, S. 2000: Seasonal variation in the Atlantic Water inflow to the Nordic Seas. ICES CM 1999/L:21. Copenhagen: International Council for the Exploration of the Sea.

Hansen, B., Larsen, K. M. H., Østerhus, S., Turrell, B. \& Jónsson, S. 1999: The Atlantic Water inflow to the Nordic seas. Int. WOCE Newslett. 35, 33-35.

Hansen, B. \& Østerhus, S. 2000: North Atlantic-Nordic seas exchanges. Prog. Oceanogr. 45, 109-208.

Hansen, B., Turrell, W. R. \& Østerhus, S. 2001: Faroe Bank Channel overflow has decreased since 1950. Nature 411, 927-930.

Hermann, F. 1967: The T-S diagram analysis of the water masses over the Iceland-Faroe Ridge and in the Faroe Bank Channel (Overflow '60). Rapports et Procès-Verbaux des Réunions 157, 139-149. International Council for the Exploration of the Sea.

Jónsson, S. 1999: The circulation in the northern part of the Denmark Strait and its variability. ICES CM 1999/L:06. Copenhagen: International Council for the Exploration of the Sea.

Kristmannsson, S. S. 1998: Flow of Atlantic Water into the northern Icelandic shelf area, 1985-1989. ICES Coop. Res. Rep. 225, 124-135.

Østerhus, S., Hansen, B., Kristiansen, R. \& Lundberg, P. 1999: The overflow through the Faroe Bank Channel. Int WOCE Newslett. 35, 35-37.

Rahmstorf, S. \& Ganopolski, A. 1999: Long-term global warming scenarios computed with an efficient coupled climate model. Clim. Change 43, 353-367.

Roach, A. T., Aagaard, K., Pease, C. H., Salo, S. A., Weingartner, T., Pavlov, V. \& Kulakov, M. 1995: Direct measurements of transport and water properties through the Bering Strait. J. Geophys. Res. 100(C9), 18443-18457.

Turrell, W. R., Hansen, B., Østerhus, S., Hughes, S., Ewart, K. \& Hamilton, J. 1999: Direct observations of inflow to the Nordic seas through the Faroe Shetland Channel 1994-1997. ICES CM 1999/L:01. Copenhagen: International Council for the Exploration of the Sea.

Worthington, L. V. 1970: The Norwegian Sea as a mediterranean basin. Deep-Sea Res. 17, 77-84. 